\title{
Endoscopic Cyanoacrylate Injection Treatment for Refractory High-risk Peptic Ulcer Bleeding by Conventional Endoscopic Therapy
}

Biguang Tuo ( $\nabla$ tuobiguang@aliyun.com )

Affiliated Hospital of Zunyi Medical University

Haijun Mou

Affiliated Hospital of Zunyi Medical University

Cheng Zou

People's Hospital of Liupanshui City

Guoqing Shi

Affiliated Hospital of Zunyi Medical University

\section{Sheng Wu}

People's Hospital of Liupanshui City

Rui Xie

Affiliated Hospital of Zunyi Medical University

Xuemei Liu

Affiliated Hospital of Zunyi Medical University

Jie Yang

People's Hospital of Liupanshui City

\section{Research Article}

Keywords: Bleeding, Endoscopic cyanoacrylate injection, Endoscopic therapy, Peptic ulcer, Rebleeding

Posted Date: January 14th, 2022

DOI: https://doi.org/10.21203/rs.3.rs-1220032/v1

License: (1) (1) This work is licensed under a Creative Commons Attribution 4.0 International License. Read Full License 


\section{Abstract}

Bleeding is a major and potentially life-threatening complication of peptic ulcer. Despite endoscopic hemostatic therapy advance, conventional endoscopic hemostatic modalities remain refractory for peptic ulcer bleeding with big size, fibrous base or in difficult-to-access anatomical locations. In this study, we attempted to evaluate the efficacy and safety of endoscopic cyanoacrylate injection treatment (ECIT) for refractory high-risk peptic ulcer bleeding by conventional endoscopic therapy. The patients with refractory high-risk peptic ulcer bleeding by conventional endoscopic therapy were carried out ECIT. The data were retrospectively collected. A total of 119 patients accepted ECIT. 74 patients $(62.18 \%)$ obtained successful intravascular injection and perivascular injection was performed in 45 patients (37.82\%). Immediate hemostatic rate for active bleeding achieved $90.91 \%$. Rebleeding rate within 30 days was $12.07 \%$. Overall successful hemostasis rate achieved $87.93 \%$. Immediate hemostatic rate and overall successful hemostasis rate in intravascular injection patients were markedly superior over perivascular injection. Rebleeding rate in intravascular injection patients was markedly lower than that in perivascular injection patients. 11 patients complicated abdominal pain and no other complication occurred. In conclusion, ECIT, especial intravascular injection, was effective and safe, with high successful hemostasis rate for refractory high-risk peptic ulcer bleeding by conventional endoscopic therapy.

\section{Introduction}

Peptic ulcer bleeding is the major and potentially life-threatening complication of peptic ulcer, with an average mortality of $10 \%^{1-3}$. Bleeding activity by Forrest classification is still the most important prognostic factor for the final outcome of the patients ${ }^{4}$. High-risk patients for persistent or recurrent bleeding are those with spurting arterial bleeding or a visible vessel at emergency endoscopy ${ }^{5}$. Endoscopic hemostatic therapy has been proven to be effective in terms of stoping active bleeding, preventing rebleeding, and avoiding the need for angiographic or surgical interventions for patients with a high risk stigmata of further bleeding ${ }^{6,7}$. The most commonly used endoscopic hemostatic modalities are epinephrine injection, thermal coagulation, and mechanical therapy with endoscopic clips. But epinephrine injection is less effective as hemoclipping or thermal coagulation due to rapid fading effect 8 . Therefore, epinephrine injection alone is no longer recommended, various guidelines recommend the combination therapy of epinephrine injection with hemostatic clips or thermal methods as conventional standard endoscopic therapy ${ }^{9-11}$. However, conventional endoscopic therapy is refractory to ulcers with a big size or a fibrous base or in difficult-to-access anatomical locations, such as the cardia, pylorus, junction of duodenal bulb and descending part, and the posterior duodenal wall, and has limited hemostatic efficacy for the bleeding of these ulcers ${ }^{7,9}$.

Cyanoacrylate is mainly used to obliterate esophago-gastric varices ${ }^{12}$. Previous case report showed that endoscopic cyanoacrylate injection could treat a giant exposed blood vessel of gastric ulcer successfully ${ }^{13}$. A retrospective investigation showed that cyanoacrylate plus adrenaline injection was a safe and effective for treatment of peptic ulcer bleeding after conventional endoscopic hemostasis failure. ${ }^{14} \mathrm{~A}$ 
prospective randomized clinical trial also showed that endoscopic cyanoacrylate injection treatment (ECIT) was effective in treating peptic ulcer bleeding ${ }^{15}$. In this study, we attempted to evaluate the efficacy and safety of ECIT for refractory high-risk peptic ulcer bleeding by conventional endoscopic therapy.

\section{Methods}

\section{Patients}

This investigation was a two center (Affiliated Hospital of Zunyi Medical University and People's Hospital of Liupanshui City) study for patients with bleeding gastric and duodenal ulcers from January 2018 to December 2020. The patients were admitted to the two hospitals because of upper gastrointestinal bleeding. After initial resuscitation and proton pump inhibitor (PPI) usage, all patients underwent emergency endoscopy within 24 hours of hospital admission and were diagnosed as bleeding gastric or duodenal ulcers. Patients with suspected malignant ulcers were excluded. The included patients all had stigmata of high-risk peptic ulcer bleeding with spurting bleeding (Forrest la) (Figure 1a and b), oozing bleeding (Forrest lb), or nonbleeding visible vessel $\geq 2 \mathrm{~mm}$ in diameter (Forrest lla) (Figure 2a and b) and were estimated by endoscopists to be refractory by conventional endoscopic therapy, because of following endoscopic features, ulcers with $\geq 2 \mathrm{~cm}$ size or a fibrous base, or located at the cardia, pylorus, or junction of duodenal bulb and descending part. After obtaining the written informed consent, ECIT for the patient was performed, irrespective of age, sex, or whether accompanied with heart, kidney, lung, and liver diseases.

Both Rockall scoring system and Blatchford scoring system were used in the study as a predictor of rebleeding and mortality.

This was an observational study and evaluated retrospectively. This study was approved by the Ethics Committees of Affiliated Hospital of Zunyi Medical University and People's Hospital of Liupanshui City. The study was conducted in accordance with the Declaration of Helsinki. Written informed consent concerning the procedure of ECIT was obtained from each patient.

\section{Device and procedure}

Endoscopic treatment was performed by using Olympus-Q260J Gastroscope. Cyanoacrylate was from Beijing Fuaile Medical Histoacryl Company (Beijing, China). Endoscopic injection needle was a disposable and transparent catheter needle from Boston Scientific (Boston Scientific Interject ${ }^{\mathrm{TM}} 25 \mathrm{ga}$ $(0.5 \mathrm{~mm}) \times 240 \mathrm{~cm}$, Boston, USA). The catheter needle channel was flushed and filled with normal saline before cyanoacrylate injection. $3.0 \mathrm{ml}$ normal saline (to ensure an adequate delivery of cyanoacrylate when injecting) and $0.25-0.5 \mathrm{ml}$ cyanoacrylate was sucked in a $5 \mathrm{ml}$ syringe on standby. Endoscopist operated Gastroscope close to bleeding ulcer and then inserted the catheter needle through gastroscopic working channel close to bleeding site. Under clear and direct vision, nurse (assistant) cooperated with the endoscopist to push out the needle core and rapidly and accurately punctured into bleeding or visible 
vessel. When seeing blood in the catheter needle, it indicated successful intravascular puncture (Figure 1c and Figure 2c). The nurse immediately and rapidly pushed out cyanoacrylate $0.25-0.5 \mathrm{ml}$ according to the endoscopist's discretion and then pulled out needle core within 3 seconds after injection. Then the endoscopist slightly pressed the injection site for 2 to 3 seconds with the needle sheath. When local mucosa colour became white or grayish white (Figure 1d and Figure 2d), it also demonstrated successful intravascular injection. If intravascular injection failed, perivascular injection was performed in 1 to 3 sites close to the bleeding point or visible vessel. The volume of perivascular injection cyanoacrylate was $0.5-1.5 \mathrm{ml}$ according to the endoscopist's discretion.

All the procedures were performed by the same group of experienced endoscopists and assistants, each of whom had performed more than 100 endoscopic injection treatments for upper gastrointestinal bleeding.

\section{Observation, follow up, and data collection}

After ECIT, all patients were intravenously given PPI for 72 hours. There was no scheduled second endoscopy unless it was necessary. In the event of hemostasis failure or rebleeding, patients were referred for angiographic embolization, surgery or conservative management. The observation and follow up of patient was achieved by direct patient review on the ward, in clinics and by telephone consultations. Patients were followed up for 30 days. The following data were collected and evaluated.

(1) Successful rate of intravascular injection: Intravascular injection success was defined as seeing blood in the catheter needle after puncture or local mucosal colour became white or grayish white after injection.

(2) Immediate hemostasis rate: Immediate hemostasis was defined as observed cessation of bleeding for patients with active bleeding (spurting or oozing bleeding) within 5 minutes after ECIT.

(3) Rebleeding rate at less than 72 hours, 4-14 days and 15-30 days: Rebleeding was defined as a subsequent and sustained drop in hemoglobin $(>20 \mathrm{~g} / \mathrm{L})$, hematemesis, hematochezia and persistent melena with ongoing hemodynamic compromise after initial ECIT ${ }^{16}$.

(4) Overall successful hemostasis rate: Overall successful hemostasis was defined as no rebleeding within 30 days after initial ECIT.

(5) Complications after ECIT.

(6) All-cause mortality within 30 days after ECIT.

\section{Statistical analysis}

The association between various factors and outcomes was analyzed by using statistical software (SPSS 21.0; IBM Corp., Armonk, New York, USA). Continuous variables are presented as median with interquartile range (IQR). Categorical variables are expressed as percentages. Separate association 
between each patient factor and the outcome was examined separately. The factors were then considered jointly in a single multivariable analysis by using logistic regression. A $P$-value $<0.05$ was considered statistically significant.

\section{Results}

\section{Clinical and endoscopic characteristics of patients}

From January 2018 to December 2020, 698 patients were admitted to the two institutions for bleeding peptic ulcers. A total of 141 consecutive patients met the inclusion criteria. Only 119 patients (33 patients with active bleeding and 86 patients with non-bleeding visible vessels) accepted ECIT and other 22 patients without obtaining informed consent were carried out epinephrine injection or directly angiographic embolization, surgery or conservative medical management. Clinical and endoscopic characteristics of 119 patients accepting ECIT are listed in Table 1. 
Table 1

Clinical and endoscopic characteristics of patients

\begin{tabular}{|c|c|}
\hline & Total patients $(n=119)$ \\
\hline Age (years), median (IQR) & $62(51-70)$ \\
\hline \multicolumn{2}{|l|}{ Sex, n (\%) } \\
\hline Male & $91(76.47)$ \\
\hline Female & $28(23.53)$ \\
\hline \multicolumn{2}{|l|}{ Main clinical presentation, $\mathrm{n}(\%)$} \\
\hline Hematemesis & $80(67.23)$ \\
\hline Only melena & $39(32.77)$ \\
\hline Shock & $18(15.13)$ \\
\hline \multicolumn{2}{|l|}{ Ulcer location, n (\%) } \\
\hline Duodenal bulb & $42(35.29)$ \\
\hline Junction of duodenal bulb and descending part & $11(9.24)$ \\
\hline Duodenal descending part & $4(3.36)$ \\
\hline Gastric antrum & $26(21.85)$ \\
\hline Gastric angulus & $11(9.24)$ \\
\hline Gastric body & $15(12.61)$ \\
\hline Gastric fundus & $4(3.36)$ \\
\hline Pylorus & $6(5.05)$ \\
\hline \multicolumn{2}{|l|}{ Forrest classification, n (\%) } \\
\hline la & $16(13.44)$ \\
\hline $\mathrm{lb}$ & $17(14.29)$ \\
\hline Ila & $86(72.27)$ \\
\hline \multicolumn{2}{|l|}{ Comorbidities, n (\%) } \\
\hline Ischemic heart diseases & $4(3.36)$ \\
\hline Heart failure & $2(1.68)$ \\
\hline Renal failure & $6(5.04)$ \\
\hline Hepatic failure & $3(2.52)$ \\
\hline
\end{tabular}




\begin{tabular}{|ll|}
\hline & Total patients $(\mathbf{n}=\mathbf{1 1 9})$ \\
\hline Respiratory failure & $5(4.20)$ \\
\hline Severe pancreatitis & $1(0.84)$ \\
\hline Hepatic and renal failure & $1(0.84)$ \\
\hline Hepatic and respiratory failure & $1(0.84)$ \\
\hline Heart and respiratory failure & $1(0.84)$ \\
\hline Rockall scores, median (IQR) & $6(5-8)$ \\
\hline Blatchford scores, median (IQR) & $12(10-14)$ \\
\hline
\end{tabular}

\section{Technical and hemostatic success and rebleeding}

Among the 119 patients, 74 patients (62.18\%) obtained successful endoscopic intravascular cyanoacrylate injection. 45 patients (37.82\%) with intravascular injection failure was performed perivascular cyanoacrylate injection.

Among 33 patients with active bleeding (Forrest la and lb), 19 patients $(57.58 \%)$ obtained intravascular cyanoacrylate injection and 14 patients (42.42\%) was performed perivascular cyanoacrylate injection. Total 30 patients $(90.91 \%, 30 / 33)$ achieved immediate hemostasis. Immediate hemostasis rate of intravascular injection was $100 \%$ (19/19), whereas perivascular injection was $78.57 \%(11 / 14)(P<0.01)$. Of the 3 patients with hemostasis failure, 1 patient was carried out surgery and 2 patients were carried out angiographic embolization, and all achieved successful hemostasis.

Of the 116 patients (30 Forrest la and Ib patients obtained immediate hemostasis and 86 Forrest lla patients), 14 patients occurred rebleeding. Overall rebleeding rate was $12.07 \%$ (14/116). Rebleeding rate of intravascular injection $(2.70 \%, 2 / 74)$ was markedly lower than that of perivascular injection $(28.57 \%$, 12/42) $(P<0.001) .102$ patients had no rebleeding and overall successful hemostasis rate of ECIT was $87.93 \%(102 / 116)$. Successful hemostasis rate of intravascular injection $(97.30 \%, 72 / 74)$ was markedly higher than that of perivascular injection $(71.43 \%, 30 / 42)(P<0.001)$ (Table 2). Among the 14 rebleeding patients, 3 patients died because of large bleeding with shock, 5 patients accepted angiographic embolization, 3 patients accepted surgery and 3 patients accepted conservative medical management. 
Table 2

Rebleeding and successful hemostasis of intravascular and perivascular injection

\begin{tabular}{|c|c|c|c|c|c|c|}
\hline & \multirow[t]{2}{*}{ Number } & \multicolumn{3}{|c|}{ Rebleeding } & \multirow{2}{*}{$\begin{array}{l}\begin{array}{l}\text { Overall } \\
\text { rebleeding }\end{array} \\
\mathrm{N}(\%)\end{array}$} & \multirow{2}{*}{$\begin{array}{l}\text { Overall successful } \\
\text { hemostasis N (\%) }\end{array}$} \\
\hline & & $<72 h$ & $\begin{array}{l}4- \\
14 d\end{array}$ & $\begin{array}{l}15- \\
30 d\end{array}$ & & \\
\hline $\begin{array}{l}\text { Intravascular } \\
\text { injection }\end{array}$ & 74 & 1 & 1 & 0 & $2(2.70)$ & $72(97.30)$ \\
\hline $\begin{array}{l}\text { Perivascular } \\
\text { injection }\end{array}$ & 42 & 8 & 4 & 0 & $12(28.57)$ & 30 (71.42) \\
\hline \multicolumn{5}{|l|}{$P$ value } & $<0.001$ & $<0.001$ \\
\hline \multicolumn{7}{|c|}{$\begin{array}{l}\text { Rebleeding, rebleeding within } 30 \text { days after achieving immediate hemostasis. Overall success } \\
\text { hemostasis, no rebleeding with } 30 \text { days after initial endoscopic injection treatment. h, hours; d, days; } \\
\mathrm{N} \text {, number. }\end{array}$} \\
\hline
\end{tabular}

\section{Complications}

11 patients (10 intravascular injection and 1 perivascular injection) occurred abdominal pain, 8 patients with mild pain, 2 patients with moderate pain and 1 patient with severe pain. All patients' abdominal pains were relieved at 1 to 4 days by PPI and symptomatic treatment. Incidence of abdominal pain in intravascular injection patients was $13.51 \%(10 / 74)$, which was markedly higher than that in perivascular injection patients $(2.22 \%, 1 / 45)(P<0.001)$. The 11 patients complicating abdominal pain were performed second endoscopy at 7 to 10 days after ECIT and all patients showed good ulcer healing sign (Figure 1e and Figure 2e). No other complications, such perforation, ectopic embolism, and so on, occurred in our patients.

\section{All-cause mortality}

In our patients, 30 day all-cause mortality was $8.40 \%$ (10/119). 3 patients directly died of rebleeding with shock after initial ECIT. 1 patient died of second rebleeding after angiographic embolization. 1 patient died of the progress of comorbidity after angiographic embolization for rebleeding. 1 patient died of the progress of comorbidity after surgery for rebleeding. 1 patient died of the progress of comorbidity after conservative management for rebleeding. Other 3 patients achieved successful hemostasis after initial ECIT, but died of the progress of comorbidities.

All-cause mortality rate of perivascular injection patients $(20 \%, 9 / 45)$ was markedly higher than that of intravascular injection $(1.35 \%, 1 / 74)(P<0.001)$. This is likely to be due to most of deaths were those who occurred rebleeding. In our 14 patients with rebleeding, 7 patients $(50 \%)$ died, whereas in 102 patients without rebleeding, only 3 patients $(2.94 \%)$ died $(P<0.001)$. 


\section{Intravascular injection success rate for Forrest classification and ulcer location}

The result showed that intravascular injection had markedly higher successful hemostasis rate than perivascular injection. We further evaluated effects of Forrest classification and ulcer location on intravascular injection success. As shown Table 3, Forrest classification had no effect on intravascular injection success, but ulcers in the gastric angulus and body had markedly high intravascular injection success rate in comparison to ulcers in other locations $(P<0.05)$ and ulcers in the pylorus and junction of duodenal bulb and descending part had lower intravascular injection success rate.

\section{Table 3}

Intravascular injection success rate for Forrest classification and ulcer location

\begin{tabular}{|llll|}
\hline Forrest classification & Number & $\begin{array}{l}\text { Intravascular injection N } \\
(\%)\end{array}$ & $\begin{array}{c}P \\
\text { value }\end{array}$ \\
\hline Ia & 16 & $9(56.25)$ & $>0.05$ \\
\hline Ib & 17 & $10(58.82)$ & \\
\hline Ila & 86 & $55(63.95)$ & \\
\hline Ulcer location & & & \\
\hline Duodenal bulb & 42 & $26(61.90)$ & $<0.05$ \\
\hline Junction of duodenal bulb and descending & 11 & $5(45.45)$ & $<0.05$ \\
\hline Dart & 4 & $2(50.00)$ & \\
\hline Gaodenal descending part & 26 & $16(61.53)$ & \\
\hline Gastric angulus & 11 & $9(81.82)$ & \\
\hline Gastric body & 15 & $12(80.00)$ & \\
\hline Gastric fundus & 4 & $2(50.00)$ & \\
\hline Pylorus & 6 & $2(33.33)$ & \\
\hline N, number. & & & \\
\hline
\end{tabular}

\section{Rebleeding and all-cause mortality for Forrest classification}


Intravascular injection patients in Forrest la, lb and lla had high successful hemostatis rate and only 2 patients in Forrest lla occurred rebleeding. There was no significant difference in rebleeding occurrence between them. However, in perivascular injection patients, rebleeding of Forrest la was markedly higher than that of Forrest lla $(P<0.05)$. There was no significant difference in all-cause mortality between them (Table 4).

\section{Table 4}

Rebleeding and all-cause mortality for Forrest classification

\begin{tabular}{|c|c|c|c|c|c|c|}
\hline \multirow{2}{*}{$\begin{array}{l}\text { Forrest } \\
\text { classification }\end{array}$} & \multirow{2}{*}{$\begin{array}{l}\text { Total } \\
\text { number }\end{array}$} & \multicolumn{2}{|c|}{ Intravascular injection } & \multicolumn{2}{|c|}{ Perivascular injection } & \multirow{2}{*}{$\begin{array}{l}\text { All cause } \\
\text { mortality N (\%) }\end{array}$} \\
\hline & & Number & $\begin{array}{l}\text { Rebleeding } \\
\mathrm{N}(\%)\end{array}$ & Number & $\begin{array}{l}\text { Rebleeding } \\
\mathrm{N}(\%)\end{array}$ & \\
\hline la & 16 & 9 & 0 & 7 & $4(57.14)$ & $2(12.50)$ \\
\hline $\mathrm{lb}$ & 17 & 10 & 0 & 7 & $3(42.86)$ & $2(11.76)$ \\
\hline Ila & 86 & 55 & 2 & 31 & $8(25.81)$ & $6(6.98)$ \\
\hline \multicolumn{3}{|l|}{$P$ value } & \multicolumn{2}{|l|}{$>0.05$} & $<0.05$ & $>0.05$ \\
\hline \multicolumn{7}{|c|}{$\begin{array}{l}\text { Rebleeding, rebleeding after endoscopic injection treatment, including not to achieve immediate } \\
\text { hemostasis. }\end{array}$} \\
\hline
\end{tabular}

\section{Rebleeding and all-cause mortality for Rockall and Blatchford scores}

Patients with both rebleeding and all-cause mortality had higher Rockall and Blatchford scores in comparison to successful hemostasis and non-mortality patients (Table 5). Multivariate analysis also showed that both Rockall and Blatchford scores were associated with increased risk of rebleeding and dying.

\section{Table 5}

Rebleeding and all cause mortality for Rockall and Blatchford scores 


\begin{tabular}{|lllllll|}
\hline & $\begin{array}{l}\text { Success } \\
\text { hemostasis }\end{array}$ & Rebleeding & $\begin{array}{l}P \\
\text { value }\end{array}$ & $\begin{array}{l}\text { Non } \\
\text { mortality }\end{array}$ & $\begin{array}{l}\text { All cause } \\
\text { mortality }\end{array}$ & $P$ value \\
\hline Patient number & 102 & 17 & & 109 & 10 & \\
\hline $\begin{array}{l}\text { Rockall scores, } \\
\text { Median (IQR) }\end{array}$ & $6(4-7)$ & $8(5-9)$ & $<0.001$ & $6(4-8)$ & $9(8-10)$ & $<0.001$ \\
\hline $\begin{array}{l}\text { Blatchford scores, } \\
\text { Median (IQR) }\end{array}$ & $12(10-13)$ & $13(12-14)$ & $<0.05$ & $\begin{array}{l}12(10- \\
13)\end{array}$ & $14(14-15)$ & $<0.01$ \\
\hline $\begin{array}{l}\text { IQR, interquartile range. Success hemostasis, achieving immediate hemostasis and no rebleeding } \\
\text { within 30 days after endoscopic injection treatment. Rebleeding, rebleeding after endoscopic injection } \\
\text { treatment, including not to achieve immediate hemostasis. }\end{array}$ & & & & \\
\hline
\end{tabular}

\section{Discussion}

In this study, our results demonstrate that ECIT can effectively stop active bleeding and preventing rebleeding for refractory high-risk peptic ulcer bleeding by conventional endoscopic therapy. To our knowledge, this is the first study to evaluate the outcomes of refractory high-risk peptic ulcer bleeding by ECIT.

Peptic ulcer bleeding remains the most common cause of upper gastrointestinal bleeding and main cause of peptic ulcer patient death. Endoscopic hemostatic treatment is currently recommended as its primary treatment ${ }^{10,11,17}$. Conventional endoscopic therapy has been proven to be effective for most bleeding peptic ulcer patients. However, successful application of mechanical and thermal device may be difficult for ulcers in difficult-to-access anatomical locations. Clips are also difficult to apply in large ulcers with hard fibrotic bases ${ }^{18,19}$. There is therefore a need to explore endoscopic hemostatic modality to improve outcomes of these refractory high-risk bleeding peptic ulcers.

Cyanoacrylate is a liquid substance which polymerizes and hardens rapidly when in contact with blood and produces a solid mass. Because the solid mass can induce vascular obliteration or strongly compress bleeding vessels, endoscopic intravascular or perivascular cyanoacrylate injection is widely used to treat esophageal and gastric varices, which can effectively stop and prevent variceal bleeding 20,21. Cyanoacrylate is also often used to occlude the major feeding artery to ulcers as embolic agent to treat bleeding peptic ulcers on doing angiographic intervention therapy ${ }^{22}$. We think that cyanoacrylate can occlude vessel to ulcer to treat bleeding peptic ulcers on angiographic intervention therapy, we also can occlude feeding vessel to bleeding ulcer with cyanoacrylate through endoscopic intravascular injection. In addition, even if it is failure to do endoscopic intravascular injection, perivascular cyanoacrylate injection-producing solid mass is non-absorbable and has a longer compressing effect on bleeding vessel in comparison to epinephrine injection. We have done endoscopic gastric and esophageal intravariceal cyanoacrylate injection for many years ${ }^{23}$, and endoscopic injection was easily carried out, 
even at difficult anatomic locations. Therefore, we attempted to treat refractory high-risk bleeding peptic ulcer by conventional endoscopic therapy through using ECIT.

Our study showed that intravascular cyanoacrylate injection success rate achieved $62.18 \%$ in 119 patients accepting ECIT and perivascular injection was performed only in 45 patients (37.82\%). Immediate hemostatic rate for active bleeding achieved $90.91 \%$. Overall rebleeding rate was $12.07 \%$ and successful hemostasis rates achieved $87.93 \%$. Rebleeding rate in intravascular injection patients was $2.70 \%$, which was markedly lower than that in perivascular injection $(28.57 \%)$. This demonstrates that ECIT, especial intravascular cyanoacrylate injection, can effectively stop active bleeding and prevent rebleeding for refractory high-risk peptic ulcer bleeding by conventional endoscopic therapy.

We further evaluated intravascular injection success in Forrest classification and ulcer location. We found that intravascular injection success was not associated with Forrest classification, but with ulcer location. There was markedly higher intravascular injection success rate in ulcers at the gastric angulus and body in comparison to ulcers at other locations, whereas there was lower intravascular injection success rate in ulcers at the pylorus and junction of duodenal bulb and descending part. It is likely to be due to the endoscopic operation is easily performed in the gastric angulus and body.

The literature regarding the efficacy of ECIT for bleeding peptic ulcers is scant. In a previous randomized trial, Lee and colleagues reported that initial hemostasis rate of ECIT for bleeding peptic ulcers achieved $95.2 \%(60 / 63)$ and rebleeding rate was $11.67 \%(7 / 60)^{15}$. However, not all patients in their study were high-risk peptic ulcer bleeding. In another retrospective study, Repici and colleagues performed endoscopic cyanoacrylate plus epinephrine injection in the base of ulcer, close to vessel or bleeding point for 18 peptic ulcer bleeding patients with failure in conventional endoscopic therapy ${ }^{14} .17$ patients obtained successful hemostasis without occurring rebleeding and no complications related to cyanoacrylate injection occurred, which demonstrated that ECIT is safe and effective in treating peptic ulcer bleeding. It is pity that there were only small patients in the study. Previous some case reports showed that endoscopic cyanoacrylate injection for bleeding gastric and duodenal ulcers resulted in the complications of duodenal ulcer perforation and abdominal arterial embolization. ${ }^{24-26}$ In our 119 patients, 10 intravascular cyanoacrylate injection $(13.51 \%, 10 / 74)$ and 1 perivascular cyanoacrylate injection patients $(2.22 \%, 1 / 45)$ occurred abdominal pain. The abdominal pains in all patients were relived at 1 to 4 days by PPI and symptomatic treatment, and endoscopy for these patients showed no significant delay in ulcer healing. No other complication occurred. We think that newly-produced cyanoacrylate has strong polymerization and can harden rapidly at 2 to 3 seconds after injection. A low dose of cyanoacrylate $(0.25-0.5 \mathrm{ml})$ injected into gastric or duodenal mucosal artery is almost impossible to induce abdominal artery embolization or ectopic embolization. Therefore, ECIT with a low dose is safe, without severe complications.

In this study, the 30-day all-cause mortality was $8.40 \%$ (10/119), which was lower than the predicted rate as per Rockall score. Most of deaths died of the progression of cormordities after rebleeding, which 
further demonstrates that rebleeding is still an important predictor of increased mortality 27,28 , and achieving primary hemostasis and preventing rebleeding are very important for reducing mortality.

We further analyzed effects of Forrest classification, Rockall and Blatch scoring on rebleeding and allcause mortality. Our patients were at high risk, with high baseline median Rockall score (6, IQR 5-8) and Blatchford score (12, IQR 10-14). The data showed that Forrest la had a higher rebleeding in comparison to other types, but there was no significant difference in all-cause mortality between Forrest classifications. Both high Rockall score and Blatchford score increased the risks of rebleeding and allcause mortality, indicating that Rockall scoring and Blockford scoring can serve as predictor of rebleeding and mortality for high-risk peptic ulcer bleeding.

Endoscopic treatment remains the primary therapy for high-risk peptic ulcer bleeding, because angiographic or surgical intervention is associated with considerable high complications. ${ }^{29}$ In order to further improve the clinical outcomes of patients with high-risk peptic ulcer bleeding, some new endoscopic hemostatic modalities, including over-the-scope clips (OTSC) and hemospray, have been developed. A recently published study showed that in Hemospray-treated 202 patients with peptic ulcer bleeding, immediate hemostasis rate was $88 \%$ (178/202), 17\% (26/154) experienced rebleeding, and overall all-cause mortality was $34 \%(59 / 175)$ within 30 days ${ }^{30}$. A previous study showed that successful hemostasis rate of OTSC treatment was $77.8 \%$ in refractory peptic ulcer bleeding with big size ${ }^{31}$. The recent study for patients with recurrent bleeding of peptic ulcers showed that the rebleeding rate of OTSC treatment was $15.15 \%(5 / 33)$ and all-cause mortality was $12.12 \%(4 / 33)^{32}$. In our study, rebleeding rate was $12.07 \%$ (14/116) and all-cause mortality was $8.40 \%$ (10/119). Despite having a high-risk population, this study was able to show superior clinical outcomes over the reported efficacy of Hemospray and OTSC for peptic ulcer bleeding. Moreover, endoscopic intravacular cyanoacrylate injection had a more superior efficacy, with $2.7 \%$ rebleeding rate and $1.35 \%$ all-cause mortality. We think that OTSC is still difficult to ulcers at some difficult anatomic locations, and also expensive for the developing countries. ECIT is easily performed even at difficult anatomic locations. Moreover, endoscopic intravascular cyanoacrylate injection is simple and safe in contrast to angiographic cyanoacrylate embolization. Therefore, it is worth to be recommended for the management of refractory high-risk peptic ulcer bleeding by conventional endoscopic therapy.

Limitation of our study is the lack of control group and randomization. In addition, cyanoacrylate injection was administered at the discretion of the endoscopist at the time of endoscopy, which can lead to selection bias. However, considering the limited data available evaluating the efficacy of ECIT as an initial therapy for refractory high-risk peptic ulcer bleeding by conventional endoscopic therapy, we think that our findings are novel and this study remains to be valuable for real-world data. Our study support that ECIT can be used as first-line therapy for refractory high-risk peptic ulcer bleeding by conventional endoscopic therapy. However, controlled randomized clinical trials are required to validate the real clinical impact of using endoscopic cyanoacrylate injection as first-line therapy in the management of refractory high-risk peptic ulcer bleeding. 


\section{Declarations}

\section{Author contributions}

M.H.: substantial contribution; participated in study design, reviewed patients, conducted literature search, reviewed all articles, helped interpret the data, wrote, and revised manuscript; C.Z., G.S., S.W., X.L., R.X., J.Y.: reviewed patients, conducted literature search, reviewed all articles, helped interpret the data, helped drafing the manuscript; B.T.: substantial contribution; participated in study design and coordination, reviewed patients, drafed and revised the manuscript. All authors approved the submission and fnal version of this manuscript.

\section{Funding information}

This study was supported by grants from the Clinical Medical Research Center of Digestive Diseases, Guizhou Province, China. The funding body had no role in the design of the study and collection, analysis, and interpretation of data and in writing this manuscript.

\section{Conflict of interests}

All authors have no conflicts of interest to disclose.

\section{Data availability}

All data generated or analysed during this study are included in this published article.

\section{References}

1. Alzoubaidi, D., Lovat, L.B. \& Haidry, R. Management of non-variceal upper gastrointestinal bleeding: where are we in 2018? Frontline. Gastroenterol. 10, 35-42 (2019).

2. Quan, S. et al. Upper-gastrointestinal bleeding secondary to peptic ulcer disease: incidence and outcomes. World. J. Gastroenterol. 20, 17568-17577 (2014).

3. Lau, J.Y. et al. Systematic review of the epidemiology of complicated peptic ulcer disease: incidence, recurrence, risk factors and mortality. Digestion. 84, 102-113 (2011).

4. Forrest, J., Finlayson, N. \& Shearman, D. Endoscopy in gastrointestinal bleeding. Lancet. 2, 394-397 (1974).

5. Chiu, P.W. \& Ng, E.K. Predicting poor outcome from acute upper gastrointestinal hemorrhage. Gastroenterol. Clin. North. Am. 38, 215-230 (2009). 
6. Hwang, J. et al. The role of endoscopy in the management of acute non-variceal upper GI bleeding. Gastrointest. Endosc. 75, 1132-1138 (2012).

7. Shi, K. et al. Systematic review with network meta analysis: dual therapy for high-risk bleeding peptic ulcers. BMC. Gastroenterol. 17, 55(2017).

8. Baracat, F. et al. Endoscopic hemostasis for peptic ulcer bleeding: systematic review and metaanalyses of randomized controlled trials. Surg. Endosc. 30, 2155-2168 (2016).

9. Sung, J.J.Y., Tsoi, K.K., Lai, L.H., Wu, J.C.Y. \& Lau, J.Y.W. Endoscopic clipping versus injection and thermo-coagulation in the treatment of non-variceal upper gastrointestinal bleeding: a meta-analysis. Gut. 56, 1364-1373 (2007).

10. Gralnek, I. et al. Diagnosis and management of nonvariceal upper gastrointestinal hemorrhage: European Society of Gastrointestinal Endoscopy (ESGE) Guideline. Endoscopy. 47, 1-46 (2015).

11. Fujishiro, M. et al. Guidelines for endoscopic management of non-variceal upper gastrointestinal bleeding. Dig. Endosc. 28, 363-378 (2016).

12. D'Imperio, N. et al. Evaluation of undiluted N-butyl-2-cyanoacrylate in the endoscopic treatment of upper gastrointestinal tract varices. Endoscopy. 28, 239-243 (1996).

13. Kurokohchi, K. et al. Successful treatment of a giant exposed blood vessel in a gastric ulcer by endoscopic sclerotherapy with N-butyl-2-cyanoacrylate. Endoscopy. 39 Suppl 1: E250 (2007).

14. Repici, A. et al. Adrenaline plus cyanoacrylate injection for treatment of bleeding peptic ulcers after failure of conventional endoscopic haemostasis. Dig. Liver. Dis. 34, 349-355 (2002).

15. Lee, K.J., Kim, J.H., Hahm, K.B., Cho, S.W. \& Park, Y.S. Randomized trial of N-butyl-2-cyanoacrylate compared with injection of hypertonic saline-epinephrine in the endoscopic treatment of bleeding peptic ulcers. Endoscopy. 32, 505-511(2000).

16. Laine, L. et al. Methodology for randomized trials of patients with nonvariceal upper gastrointestinal bleeding: recommendations from an international consensus conference. Am. J. Gastroenterol. 105, 540-550 (2010).

17. Laine, L. \& Jensen, D.M. Management of patients with ulcer bleeding. Am. J. Gastroenterol. 107, 345-360 (2012).

18. Chiu, P.W. Endoscopic management of peptic ulcer bleeding: recent advances. Clin. Endosc. 52, 416418 (2019).

19. Sung, J.J.Y., Laine, L., Kuipers, E.J. \& Barkun, A.N. Towards personalised management for nonvariceal upper gastrointestinal bleeding. Gut. 70, 818-824 (2021).

20. Hu, Z., Zhang, D., Swai, J., Liu, T. \& Liu, S. Risk of rebleeding from gastroesophageal varices after initial treatment with cyanoacrylate; a systematic review and pooled analysis. BMC. Gastroenterol. 20, 181 (2020).

21. Ríos Castellanos, E., Seron, P., Gisbert, J.P. \& Bonfill, C.X. Endoscopic injection of cyanoacrylate glue versus other endoscopic procedures for acute bleeding gastric varices in people with portal hypertension. Cochrane. Database. Syst. Rev. 5: CD010180 (2015). 
22. Loffroy. R. et al. Ten-year experience with arterial embolization for peptic ulcer bleeding: N-butyl cyanoacrylate glue versus other embolic agents. Eur. Radiol. 31, 3015-3026 (2021).

23. Zhang, M. et al. Clip-assisted endoscopic cyanoacrylate injection for gastric varices with a gastrorenal shunt: a multicenter study. Endoscopy. 51, 936-940 (2019).

24. Cheah, W.K., So, J., Chong, S.M. \& Goh, P. Duodenal ulcer perforation following cyanoacrylate injection. Endoscopy. 32, S23 (2000).

25. Lee, G.H. et al. Life-threatening intraabdominal arterial embolization after histoacryl injection for bleeding gastric ulcer. Endoscopy. 32, 422-424 (2000).

26. Peixoto, P. et al. Embolic complications associated with endoscopic injection of canoacrylate for bleeding duodenal ulcer. Endoscopy. 40 Suppl 2, E126 (2008).

27. Elmunzer, B.J., Young, S.D., Inadomi, J.M., Schoenfeld, P. \& Laine, L. Systematic review of the predictors of recurrent hemorrhage after endoscopic hemostatic therapy for bleeding peptic ulcers. Am. J. Gastroenterol. 103, 2625-32 (2008).

28. Chiu, P.W. \& Chan, F.K. Upper gastrointestinal bleeding: risk scores and clinical judgment in predicting outcomes of UGIB. Nat. Rev. Gastroenterol. Hepatol. 11, 399-401 (2014).

29. Nykänen, T., Peltola, E., Kylänpää, L. \& Udd, M. Bleeding gastric and duodenal ulcers: case-control study comparing angioembolization and surgery. Scand J. Gastroenterol. 52, 523-530 (2017).

30. Hussein, M. et al. Hemostatic spray powder TC-325 in the primary endoscopic treatment of peptic ulcer-related bleeding: multicenter international registry. Endoscopy. 53, 36-43 (2021).

31. Chan, S.M., Chiu, P.W.Y., Teoh. A.Y.B. \& Lau, J.Y.W. Use of the over-the-scope clip for treatment of refractory upper gastrointestinal bleeding: a case series. Endoscopy. 46, 428-431(2014).

32. Schmidt, A. et al. Over-the-scope clips are more effective than standard endoscopic therapy for patients with recurrent bleeding of peptic ulcers. Gastroenterology. 155, 674-86.e6 (2018).

\section{Figures}





Figure 1

Effective treatment with endoscopic intravascular cyanoacrylate injection for bleeding duodenal ulcer. (a) Forrest la bleeding from a large ulcer in the duodenal bulb. (b) Spurting bleeding. (c) Intravascular puncture with seeing blood in catheter needle. (d) Local mucosal colour became white after intravascular cyanoacrylate injection. (e) Endoscopy showed ulcer healing sign and cyanoacrylate residue at injecting site at 7 days after endoscopic injection treatment. 

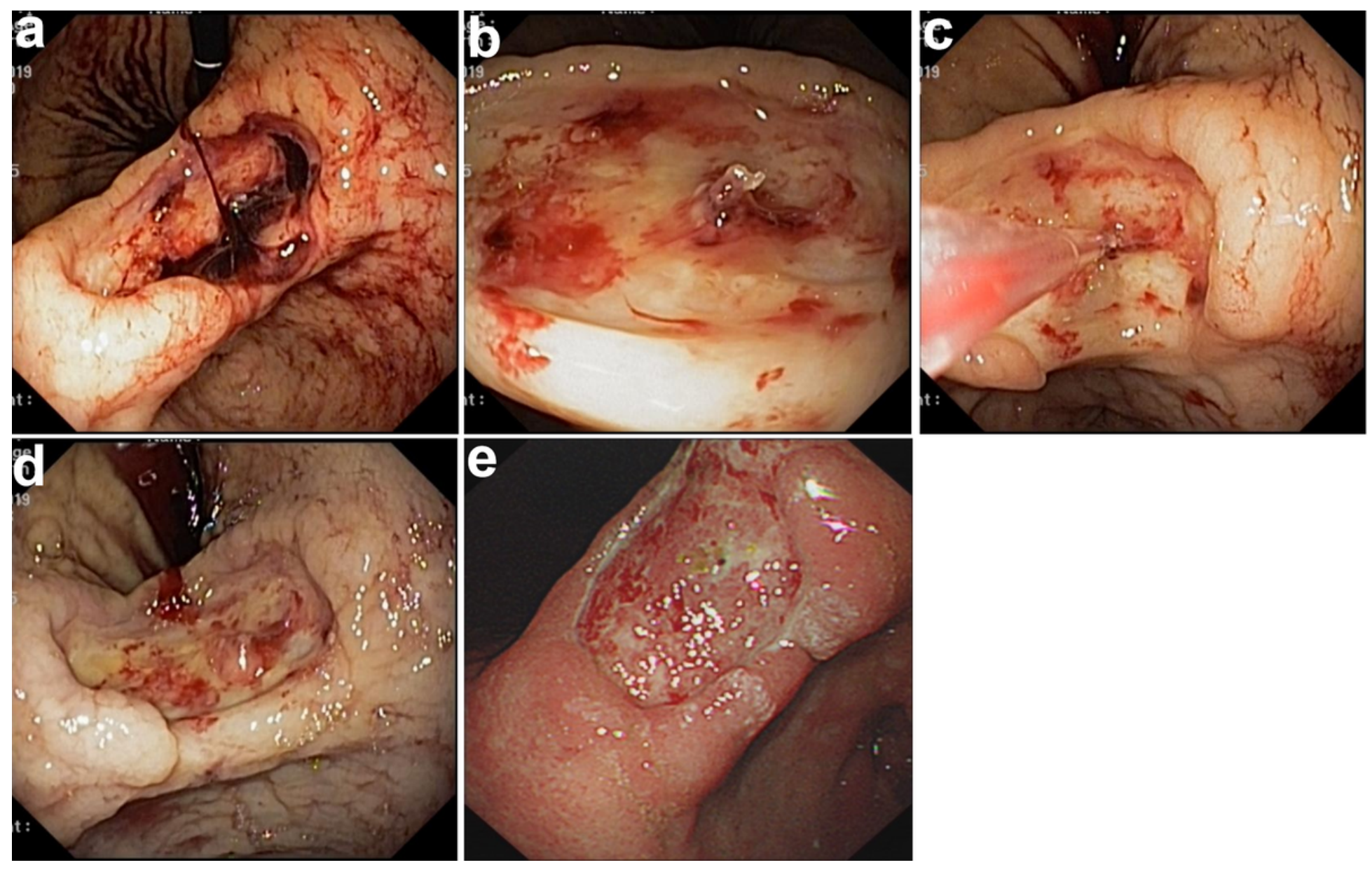

\section{Figure 2}

Effective treatment with endoscopic intravascular cyanoacrylate injection for bleeding gastric ulcer. (a) Forrest lla bleeding from a large ulcer in the gastric angulus. (b) visible vessel. (c) Intravascular puncture with seeing blood in catheter needle. (d) Local mucosal colour became grayish white after intravascular cyanoacrylate injection. (e) Endoscopy showed ulcer healing sign at 10 days after endoscopic injection treatment. 